AUTOR

Óscar Rico

Bodelón ${ }^{\circledR *}$

ricobodelon@hotmail. com

${ }^{\circledR}$ Autor de contacto

Doctor en História de América por

la Universidad de

Salamanca. Investigador miembro del Grupo de Investigación

BRASILHIS, centra su trabajo en las cuestiones de límites y en las expediciones militares españolas al sur de Brasil en el siglo XVIII

\section{Repercusiones de la Unión lbérica en el sur de Brasil: el caso de Santa Catarina}

\author{
Repercussões da União Ibérica no sul do Brasil: o caso de Santa Catarina \\ Impact of the Iberian Union on Southern Brazil: the case of Santa Catarina
}

\section{RESUMEN}

Cuando los españoles conquistaron la isla de Santa Catarina en 1777 ya hacía mucho tiempo que habían perdido las opciones de dominar este importante puerto en la ruta hacia el Río de la Plata. Fue durante el período de la Unión de las Coronas Ibéricas (1580-1640) cuando se abandonaron los planes castellanos para impulsar un enclave atlántico con el que se pretendían acortar las comunicaciones con Asunción, y cuando, por otra parte, también se desarrolla la acción de los bandeirantes en la Guairá y la de los comerciantes portugueses en Buenos Aires. Tres elementos que resultarán determinantes para la posterior y definitiva inclusión de los territorios situados al sur de la capitanía de São Vicente en la esfera colonial luso-brasileña.

\section{RESUMO}

Quando os espanhóis conquistaram a ilha de Santa Catarina, em 1777, fazia já muito tempo que haviam perdido a oportunidade de dominar esse importante porto na rota até o Rio da Prata. Foi durante o período da União das Coroas Ibéricas (1580-1640) que se abandonaram os planos espanhóis para impulsionar um enclave atlântico com o qual pretendiam estreitar as comunicações com Assunção, e quando, de outro lado, também de desenvolve a ação dos bandeirantes na Guairá e a dos comerciantes portugueses em Buenos Aires. Três elementos que resultarão determinantes para a posterior e definitiva incluso dos territórios situados ao sul da capitania de São Vicente na esfera colonial luso-brasileira.

\section{ABSTRACT}

When the Spaniards conquered Santa Catarina Island in 1777 it had already been a long time since they had lost their chances to control this important port along the route to the Rio de la Plata estuary. It was during the period of Iberian Union (1580-1640) when the Castilians abandoned their plans to propel an Atlantic outpost to shorten the communications between Spain and Asuncion, and also when the Bandeirantes in the Guairá region and the Portuguese merchants in Buenos Aires were operating. These three elements were to be decisive in the subsequent and definitive inclusion of the territories located south of the São Vicente captaincy in the Luso-Brazilian colonial context. 


\section{Introducción}

En el curso de nuestras investigaciones sobre la conquista española de la isla de Santa Catarina de 1777 y la ocupación militar subsiguiente hemos tenido que estudiar con suma atención los antecedentes del episodio². Examinando la dinámica de la colonización desde el siglo XVI y la pugna hispano-portuguesa en las tierras meridionales de Brasil encontramos las claves explicativas que permiten conocer algunas de las causas profundas de aquella invasión.

Durante el siglo XVI y casi todo el XVII prácticamente quedó al margen del proceso de colonización un territorio que el norteamericano Alden denominó Debatable Lands y que se ubica en el espacio limitado al Este por el océano Atlántico, al Norte por la parte meridional de la capitanía de São Vicente y la zona de la Guairá, al Oeste por los ríos Uruguay y Paraná, y al Sur por el Río de la Plata ${ }^{3}$. Aquí nos centraremos en las consecuencias o manifestaciones que el período de la Unión lbérica tuvo en este territorio, atendiendo especialmente a lo que aconteció en la isla de Santa Catarina y la parte continental inmediata. Pero para comprender mejor el punto de partida del período 1580-1640 analizaremos el sustrato histórico viendo los esfuerzos previos de los castellanos por establecer algún núcleo permanente en la costa del actual Estado de Santa Catarina como escala hacia el Río de la Plata.

La Unión Ibérica presenta un enorme interés para el estudio del conflicto limítrofe hispanoportugués al norte del Río de la Plata. En esta etapa se manifiesta un abandono o desinterés castellano por la Banda Oriental, la Guairá y la isla de Santa Catarina, la extensión de la esfera colonial luso-brasileña por la acción de los bandeirantes y en tercer lugar una provechosa experiencia comercial de los portugueses en Buenos Aires. El alcance de estas realidades se percibirá en toda su dimensión en la etapa posterior, cuando la fundación de la Colonia del Sacramento inaugure una nueva fase más dinámica y conflictiva que terminará conduciendo a la segunda campaña del general Cevallos y al Tratado de San lldefonso.

\section{La isla y el estuario, 1500-1580}

La isla de Santa Catarina se halla muy cerca del lugar donde la línea imaginaria del Tratado de Tordesillas cortaba el continente americano en su parte meridional. Otro tratado, el de Alcañices, había hecho de la ibérica una de las fronteras más antiguas de Europa, pero los nuevos límites al otro lado del Atlántico arrastrarán indefinición y polémica hasta los últimos compases del período colonial. Hoy sabemos que según el Tratado de 1494 las tierras que conforman el actual estado brasileño de Rio Grande do Sul pertenecían a la Corona de Castilla, mientras que la isla de Santa Catarina entraba dentro del área portuguesa.

En todo caso, muy pronto se hizo evidente que la exacta observancia de aquel tratado resultaba una quimera. Al margen de que el resto de monarcas europeos no acataron nunca un acuerdo que se había gestado sin tener en cuenta sus intereses, éste contenía numerosas ambigüedades e imprecisiones: no se decía desde qué isla habían de comenzar a contarse las 370 leguas, qué tipo de legua se emplearía y cómo se traduciría en grados 
de meridiano, y no se tuvo en cuenta que los instrumentos técnicos de la época no permitían hacer mediciones precisas. Hallar la longitud exacta fue un auténtico desafío que no se pudo resolver de modo plenamente satisfactorio hasta el siglo XVIII a pesar de que monarcas como Felipe II de España y su sucesor Felipe III -que convocó un concurso al que concurrió el famoso astrónomo e inventor Galileo Galileillegaron a ofrecer valiosas recompensas a quien fuese capaz de determinar de una manera convincente la longitud de un barco en alta mar ${ }^{4}$.

Quienes estaban en la vanguardia de las técnicas de navegación durante la segunda mitad del siglo XV eran los portugueses. $Y$ supieron aprovecharlo. Desde que Vasco da Gama inauguró la ruta con Asia circunnavegando África la Corona de Portugal no dejó de apoyar sus intereses en la zona. O achamento de Brasil no cambió esta tónica porque maderas, plumas y pieles de animales eran artículos menos valiosos que las especias, sedas o piedras preciosas que en pequeñas cantidades alcanzaban precios exorbitantes en Europa. Castilla, por su parte, enviará expediciones buscando un paso hacia las verdaderas Indias del otro lado del Pacífico desde que Vasco Núñez de Balboa contemplase por primera vez los Mares del Sur.

Los primeros navegantes que visitaron el puerto de Santa Catarina y la costa meridional de Rio Grande do Sul y Uruguay pretendieron sucesivamente explorar la costa, hallar un paso hacia Oriente y luego aventurarse en el gran estuario y su red fluvial. Los portugueses exhibieron la misma precocidad en surcar el litoral sudamericano que habían mostrado durante toda la carrera ultramarina. Al conocer el hallazgo efectuado por Alvares Cabral, Manuel I preparó una misión de exploración. Parece que fue encargada a Gonçalo Coelho, quien alcanzó Cananéia ${ }^{5}$, pero hay quien atribuye este cometido a Gaspar de Lemos ${ }^{6}$, algunas de cuyas embarcaciones habrían recorrido la costa riograndense. Más adelante, alrededor de 1512-1514, otras expediciones portuguesas llegaron al gran estuario (la de Fröes y João de Lisboa) o incluso a la Patagonia (Nuno Manuel, Cristóbal de Haro y otra vez João de
Lisboa). Pero no fueron sólo portugueses los que llevaron tempranamente sus naves al litoral meridional de Brasil. Muy probablemente fue de la zona costera próxima a Santa Catarina desde donde Gonneville llevó a Europa en 1504 a Essomericq, el joven hijo de un cacique carijó que un día se convertirá en noble de Francia?.

Más que simple punto de paso, su ubicación geográfica, la aptitud de sus ensenadas para cobijar varias embarcaciones, la naturaleza pródiga para proveerse de víveres y el carácter pacífico y colaborador de los indios del grupo tupí-guaraní que la habitaban, los carijós, convirtieron a la isla de Santa Catarina en estación casi obligada antes de que los navegantes prosiguiesen la singladura hacia las aguas meridionales ${ }^{8}$ de mayor peligrosidad, a las que se accedía después de una agotadora y en ocasiones no menos azarosa travesía oceánica.

Aunque otros exploradores estuviesen antes en él quien pasa por ser el "descubridor" del Río de la Plata es Juan Díaz de Solís, piloto mayor de la armada de Castilla que tratando de hallar un paso hacia Oriente por Sudamérica entró en el estuario y remontó el Paraná. Tras la consumación de su truculento final, devorado por los guaraníes en 1516, los supervivientes trataron de regresar pero naufragaron frente a Santa Catarina y dieciocho de ellos pasaron a residir entre los carijó, infiriendo por sus indicaciones que en el continente existía una sierra con cerros de plata. El mito ya circulaba antes pero despertará desmesuradas ansias de riqueza excitando la imaginación de los europeos a raíz del regreso con un tesoro considerable de algunos de los indios que habían acompañado a uno de esos náufragos, el portugués Aleixo Garcia, que pereció al regresar de su viaje por tierra hasta el Paraguay e incluso el Alto Perú9.

A causa de la fascinación de la "Sierra de plata" se desviarán algunas expediciones enviadas en principio desde España hacia las islas de la Especiería, no solo detonante de la carrera ultramarina sino también el espacio del orbe donde inicialmente se planteó una disputa seria sobre el área reservada a cada reino en virtud del Tratado de 1494. Antes 
de alcanzar el Acuerdo de Zaragoza, el 22 de abril de 1529, por el cual el emperador Carlos I de España y V de Alemania, siempre con problemas de liquidez, vendió a João III unos derechos sobre las islas Molucas que en realidad no tenía -como tampoco los tendrá su hijo Felipe sobre las Filipinas-, hubo largas negociaciones desde que en 1522 se confirmó la esfericidad del mundo y la posibilidad de alcanzar Oriente navegando hacia Occidente. Para realizar una segunda vuelta al mundo y defender los supuestos derechos españoles en el Pacífico se organizó otra expedición; uno de sus barcos, el de Rodrigo de Acuña, arribó en el llamado "puerto de los Patos", Santa Catarina, donde todavía había náufragos de la expedición de Solís. Y poco después, en 1526, llega al mismo puerto Sebastián Caboto, que había firmado un asiento con el emperador para comerciar en las Molucas. Habiendo sufrido un percance que le hizo perder su nave capitana, Caboto decidió abandonar el objetivo expreso de su viaje y poner rumbo al río de Solís, de cuyas riquezas le hablaron dos de aquellos náufragos ${ }^{10}$. Caboto había ido bautizando lugares de la costa meridional de Brasil. Uno de ellos fue precisamente "Santa Catalina" en homenaje a su esposa, Catalina Medrano, que cumplía años coincidiendo con la presencia de Caboto en esa isla ${ }^{11}$, que en adelante, aunque no inmediatamente, así pasará a ser conocida.

Lejos de abdicar de sus derechos, la Corona de Portugal se esforzó por reafirmarlos a causa de la amenaza que suponían las actividades de exploradores castellanos y comerciantes franceses. Durante la expedición promovida por João III para asegurar las tierras de la costa de Brasil incluidas en la demarcación portuguesa y consolidar asentamientos permanentes, Martim Afonso de Sousa, el jefe de la misma, designará como "Rio de São Pedro" a la Laguna de los Patos en honor de su hermano Pero Lopes de Sousa, fundará São Vicente y poco después se ordenará al grupo de españoles de Iguapé que jure obediencia al rey portugués por hallarse en territorio bajo su soberanía. La más meridional de las quince porciones de tierra asignadas a doce donatarios en 1534 fue la de Santo Amaro y Santana, que discurría desde Cananéia y comprendía el litoral de los actuales estados de Paraná y Santa Catarina. Como desde la expedición de los hermanos Sousa los portugueses dejaron de frecuentar el Río de la Plata también la isla de Santa Catarina estará por un tiempo dentro del ámbito de acción castellano.

En efecto, la actividad de los hermanos Sousa fue un auténtico revulsivo para la Corona de Castilla, que durante las siguientes tres décadas pretenderá crear asentamientos costeros en el sur de Brasil y a corto plazo actuó como catalizador para el envío de una nueva expedición. Carlos V dio jurisdicción al Adelantado del Río de la Plata, Pedro de Mendoza, sobre un vasto territorio cuyos márgenes septentrionales estaban al sur de Cananéia y al norte de Santa Catarina. Mendoza impulsó la primera fundación de Buenos Aires (1536), envió a Juan de Salazar -el fundador de Asunción (1537)- en auxilio del que había ido en pos de la Sierra de la Plata -Juan de Ayolas-, y en vista de la dificultad para conseguir víveres por la hostilidad de los indígenas encargará a su sobrino Gonzalo obtenerlos en la isla de Santa Catarina.

El segundo Adelantado fue el famoso Alvar Núñez Cabeza de Vaca. Los hechos que envuelven su presencia en la isla y su no menos célebre viaje por tierra son una buena muestra de la importancia que Santa Catarina y su orla continental tuvieron en las tentativas castellanas por conservar y poblar las vastas y desconocidas regiones entre Asunción y el Atlántico. A finales de marzo de 1541 llegó a la isla y tomó posesión de ella en nombre de Carlos I, al igual que de una amplia zona situada al norte de la isla y al sur de São Vicente:

"[Cabeza de Vaca] pasó por el río y bahía que dicen de San Francisco, el cual está [a] veinticinco leguas de la Cananea, y de allí fue la armada a desembarcar en la isla de Santa Catalina (...) con hartos trabajos y fortunas que por el caminó pasó (...) y dio a entender a los indios como iba por mandado de Su Majestad (...) y tomó posesión de ella, y así mismo del puerto que se dice de la Cananea, que está en la costa del Brasil en veinticinco grados, (...) cincuenta leguas de la isla de Santa Catalina"12. 
En Santa Catarina Cabeza de Vaca tuvo noticias importantes, lo cual viene a subrayar el papel de aquella en la red de comunicaciones que envolvía el Río de la Plata, Asunción y la costa atlántica. En mayo de 1541 llegaron a la isla nueve españoles huyendo de Buenos Aires que comunicaron las dificultades por las que pasaba el presidio, la nueva jefatura de Domingo de Irala y el resguardo del grueso de los castellanos en la ciudad de la Asunción, que había desbancado a Buenos Aires como centro colonial. Durante el medio año que pasó en la isla mantuvo buenas relaciones con sus habitantes, quienes le indicaron la existencia de un antiguo camino que empezando a menos de veinte leguas al norte de la isla le permitiría acceder por interior del continente allí donde deseaba llegar: "Le pareció que para con mayor brevedad socorrer a los que estaban en la ciudad de la Asunción y a los que residían en el puerto de Buenos Aires, debía buscar camino por la tierra firme"13. Más que un viaje fue una epopeya que emprenderá con algunos guías indígenas y doscientos cincuenta soldados. Antes de alcanzar Asunción, ya en 1542, sus hombres habían avanzado durante más de cuatro meses, recorriendo unos dos mil kilómetros y pudiendo contemplar las cataratas del Iguazú. Todo ello sin olvidarse de lanzar las bases de una soberanía que no estaría destinada a perdurar: "De los cuáles pueblos en nombre de Su Majestad el gobernador tomó la posesión, como tierra nuevamente descubierta, y la intituló y puso por nombre la provincia de Vera"14.

Pasaron algunos años hasta que, vacante la gobernación de la provincia del Río de la Plata y del Paraguay, el rey castellano acordó con Juan de Sanabria unas capitulaciones para gobernarla y explorar y poblar doscientas leguas desde los $31^{\circ}$ de altura "hacia la equinoccial". Sanabria se comprometía a constituir un pueblo "en el puerto de San Francisco", cerca "de la isla que dicen de Santa Catalina", y otro a la entrada del Río de la Plata ${ }^{15}$, pero falleció antes de ponerse en marcha. El proyecto siguió adelante porque el rey concedió a Diego de Sanabria, hijo de aquel, unas capitulaciones similares a las anteriores. Parte de la expedición, con Mencía Calderón al frente y el famoso aventurero alemán Hans
Staden alistado de arcabucero, llega alrededor de 1550 a Santa Catarina, pasando unos dos años en la isla y el continente adyacente hasta que el grupo es trasladado a São Vicente antes de que una sección del mismo repita la marcha terrestre de Cabeza de Vaca. En ese contexto se inscribe la existencia de un fugaz núcleo de población en torno a la actual localidad de São Francisco do Sul, en el Estado de Santa Catarina.

El "Río de San Francisco" de las fuentes españolas no debía estar lejos del actual São Francisco do Sul ni de donde Cabeza de Vaca emprendió su viaje terrestre imitado después por el grupo de Mencía Calderón. "San Francisco de Ibiazá" intentó desenvolverse entre grandes dificultades a las que no fueron ajenos ataques de piratas franceses y el hostigamiento de portugueses. Ataques coetáneos pueden rastrearse en los archivos españoles, como aquel efectuado contra el denominado "Puerto de Viaçá" saldado con el secuestro de españoles e indios en torno a $1550^{16}$. San Francisco de Ibiazá declinará y su población se replegará a Asunción. De esta misma ciudad habían llegado los españoles que comerciaban alrededor del río Paraná y que fueron expulsados por el gobernador Tomé de Sousa, que intentó bloquear el camino que unía la costa con aquélla. Poco antes de regresar a Portugal, informando de que había una "povoação grande de castelhanos" demasiado cerca de São Vicente, Tomé de Sousa se permitió la licencia de decir que parecía cosa de hechizo que no pudiese su rey despegarse de los castellanos en ninguna parte ${ }^{17}$, así en el Viejo como el Nuevo Mundo. Su llegada en 1549 demostró que la Corona portuguesa pretendía crear una estructura de poder colonial que vigilase las costas e impulsase el poblamiento, y ciertamente, durante las décadas de 1540-1560 éste se intensificó en la costa de la capitanía de São Vicente con la elevación a la categoría de vila de Santos o Itanhaém.

Otras poblaciones fueron creadas entonces en el espacio colonial hispanoamericano. La plata y la sierra mítica asociada a ella en el subconsciente de los europeos finalmente sí existían: el cerro del Potosí y sus inmediaciones. Aunque es 
probable que la decepción de los españoles de la zona de Asunción cuando descubrieron que otros españoles ya habían empezado a explotar esa plata poco antes accediendo desde el Perú solo fuese comparable a la intensidad del deseo que habían albergado de haber sido ellos sus descubridores. Es interesante constatar que en un primer momento, lejos de perder importancia, la zona de la Guairá y la costa del actual Estado de Santa Catarina cobraron protagonismo por motivos técnicos y geoestratégicos. Adentrarse en el Río de la Plata implicaba un riesgo para los barcos por los temporales y los fondos. Las embarcaciones utilizadas en los viajes llegaban a América muy maltrechas por los embates del océano, por lo que era necesario repararlas en algún punto de la costa brasileña. A esto hay que agregar que para acortar las comunicaciones entre los nuevos centros mineros y España, vía Asunción, se buscó una ruta fluvial que conectase con algún punto de la costa atlántica de Brasil como ese "Río de San Francisco". Hacían falta poblaciones intermedias y los primeros esfuerzos en este sentido fueron los realizados por Domingo Martínez de Irala, que posiblemente también envió agentes a Santa Catarina para persuadir a los carijós de que prestasen apoyo a los barcos que llegasen desde España, si bien no disponía de medios suficientes para apoyar la colonización de aquella ${ }^{18}$. Los gobernadores que sucedieron a Irala prosiguieron con esta política, de manera que en la región de GuairáParaguay aparecieron una serie de núcleos como Villa Rica del Espíritu Santo que, fundada en 1576, se convirtió en capital de todo el departamento de la Guairá, ubicada en el actual Estado de Paraná.

En tiempos Felipe II de España se siguió impulsando la fundación de poblaciones en la costa atlántica próxima a Santa Catarina. Al poco de iniciar su reinado otorgó a Jaime Rasquin, gobernador in pectore del Río de la Plata, una capitulación para que poblase cuatro puntos, uno de ellos "un pueblo en la costa del Brasil de nuestra demarcación en la parte que dicen San Francisco y otro treinta leguas más arriba hacia el Río de la Plata donde dicen El Viasá (sic), que por otro nombre se llama el puerto de los Patos"19. Se hacía especial hincapié en el primero, allí donde los herederos de Sanabria no habían tenido éxito, un núcleo que conjugase la asistencia a los barcos que habían hecho el viaje transoceánico y la comunicación terrestre con Asunción. Pesaba además un factor adicional: el apoyo total a esa empresa de Jaime Rasquin, quien al opinar sobre los mejores medios de hacer progresar la región del Río de la Plata mostró una gran confianza en las posibilidades de aquel lugar por varias razones:

Unas ya las conocemos:

"Esta población importa mucho porque los Portugueses que están vecinos no lo pueblen y por la seguridad grande que el puerto tiene para ir y venir los navíos, y por el gran trato y contratación que de aquel puerto habría adelante, así para la misma tierra, como para las Charcas, Provincia de Chile y estrecho de Magallanes"20.

Y otras las podíamos intuir:

"Conviene principalmente poblar el puerto de San Francisco en la costa del Brasil, que es dentro de la demarcación de Vuestra Majestad y en el Biasá [sic] o puerto de don Rodrigo, que es sesenta leguas hacia el Río de la Plata (...) y poblándose en San Francisco se evitaría que los portugueses juntamente con los tupís no destruyan los reinos y provincias (...). Poblando este puerto (...) no podrían ir a dicha tierra a poblarla franceses ni portugueses (...). Y a veinte leguas del puerto de San Francisco para ir el camino de Ontiveros y de la Ciudad de la Asunción hay muy grandes campos para criar infinitos ganados"21.

Lo que Rasquin estaba planteando, en suma, era una acción colonizadora que, caso de tener vocación de perdurabilidad, hubiese lanzado las bases de una ocupación efectiva de la zona de la Guairá y del norte del Río de la Plata. O, en sus propias palabras:

"San Francisco en 26 grados (...). La ciudad de la Asunción en el río Paraguay en 25 grados. Ontiveros en el río grande 
[Paraná] en 23 grados. (...) Se quedan los portugueses con lo que han poblado en la costa, y atajándoles el camino y entrada de la tierra adentro hácese a Vuestra Majestad muy gran servicio. $Y$ es la tierra tan grande y espaciosa que en ella se pueden poblar muchos pueblos"22.

Las recomendaciones de Rasquin fueron muy tenidas en cuenta, tal y como revela el cariz de las instrucciones y órdenes que recibió. Rasquin abogaba por construir ingenios de azúcar y se acordó incluir material necesario para hacer dos de ellos en San Francisco y otro más en el "Puerto de los Patos". En todo caso, nada de lo estipulado pudo llevarse a efecto puesto que durante la travesía oceánica, en 1559, surgieron una serie de problemas que acabaron desbaratando la pequeña flotilla que encabezaba, que terminó arribando en La Española ${ }^{23}$.

Puede que la última opción seria que los castellanos tuvieron de establecer un asentamiento en la isla de Santa Catarina antes de que los portugueses volviesen a posar sus ojos sobre ella se produjese con ocasión de la travesía de Juan Ortiz de Zárate, que había firmado en 1569 un asiento con Felipe II para gobernar y poblar las regiones que el anterior monarca "dio y concedió al gobernador don Pedro de Mendoza y después de él a Alvar Núñez Cabeza de Vaca y a Domingo de Yrala"24. Zárate se comprometió a llevar quinientos españoles y a poblar dos asentamientos. $Y$ aunque ninguno había de estar en la costa de Santa Catarina todavía pudo haber tenido consecuencias el viaje cuando, en 1573, sus barcos "la primera tierra que tomaron fue Sancta Cathalina, que es en la costa del Brasil, (...) donde invernaron y estuvieron seis meses" 25 antes de proseguir el viaje hacia el Río de la Plata sin dejar ningún poblado de entidad después de una estancia relativamente prolongada.

Así pues, el fruto de estas tentativas, proyectos y posibilidades colonizadoras fue estéril con el resultado de que la costa que se extendía desde Cananéia a la ribera del Río de la Plata era prácticamente una tierra ajena al poblamiento europeo -pero no a su influencia- en el último cuarto del siglo XVI, cuando el desarrollo de los acontecimientos en el marco político ibérico conduzca a la Monarquía Dual. Si de un lado la capitanía portuguesa de Brasil más meridional estaba casi abandonada, por el otro, según va dicho, aunque los españoles hubiesen considerado que la isla de Santa Catarina estaba dentro de su jurisdicción y parecía factible que el territorio de la Guairá y su costa atlántica, el Ibiazá, pudieran oscilar hacia la esfera colonial castellana, la situación real de ese espacio dejaba abierta a los portugueses la posibilidad de ocuparlo en el futuro. Puede decirse que no se sabía a ciencia cierta a quién pertenecía Santa Catarina. Esta disputa latente o dominio lábil halla curiosa expresión en el topónimo híbrido que figura en uno de los primeros atlas de la Historia moderna, el Theatrum Orbis Terrarum del flamenco Abraham Ortelius, cuya primera versión fue publicada en 1570. Como la propia isla en esa época, el nombre que se le asigna ("S. Catelina"), no es ni plenamente castellano ni tampoco portugués, pero parecía ser más lo primero que lo segundo. Algo que ya no sería posible sostener desde 1640. Veamos por qué.

\section{Reflejos de la unión ibérica al norte del río de la plata}

Nieto de Manuel I y tío del rey Sebastián, en 1581 Felipe II impuso sus derechos a la Corona de Portugal. El cambio fue relativo: Portugal siguió gobernándose con leyes propias y funcionarios portugueses ${ }^{26}$. El advenimiento de la unión dinástica fue aceptado en Brasil "sem reservas -mas, de igual modo, sem demasiado calor-" ${ }^{27}$ hasta la oposición que luego suscitará el propósito centralizador de Madrid hacia la década de $1620^{28}$. Este período tiene especial interés para nuestro estudio por tres hechos que pasamos a exponer individualmente. 


\section{- Desinterés castellano por las 'Debatable Lands'}

Además de la muerte del cardenal Enrique, el otro hecho trascendental que trajo el año de 1580 fue la segunda y definitiva fundación de Buenos Aires por Garay. A partir de ahora los castellanos hacen a un lado las antiguas aspiraciones sobre el Río de San Francisco en la costa de Brasil y los bonaerenses apenas utilizarán el margen septentrional del Río de la Plata para proveerse de leña, carbón, maderas, ganado vacuno y cueros sin que haya una tentativa colonizadora firme. En todo caso, por el momento tampoco los portugueses mostrarán excesivo entusiasmo por colonizar los territorios situados al sur de Cananéia, el límite de sus dominios a finales del siglo XVI. Las razones residen en la falta de algún producto exportable que hiciese rentable la colonización de ese espacio meridional y en la mayor rentabilidad que entrañaba el trato comercial directo con Buenos Aires, como luego veremos.

Buenos Aires será un centro político regional más alejado de la Guairá que Asunción. En 1617 fueron segregadas la Gobernación del Río de la Plata y la de Guairá o del Paraguay. Las principales poblaciones de ésta, Asunción aparte, eran Villa Rica del Espíritu Santo, Ciudad Real de Guairá y Santiago de Jerez, ubicadas en actual territorio brasileño. Sin plata que explotar y con el nuevo puerto para introducir mercancías aguas arriba del Paraná, el territorio sobre el que tiempo atrás se proyectó la construcción de una especie de corredor político-económico se convertía en un lugar aislado. Máxime al recrudecerse los ataques de vicentinos (luego llamados paulistas) e indios sobre villas españolas y reducciones jesuíticas.

Durante el gobierno filipino de Portugal sólo habrá contados proyectos desde Buenos Aires y Paraguay para que la isla de Santa Catarina y la parte continental adyacente fuesen dominios efectivos de Castilla. Será incapacidad práctica la que lleve al abandono de la empresa. Al evaluar el estado de las provincias del Río de la Plata el franciscano Juan Rivadeneyra comunicaba a Felipe II en 1581 que "el primer gobierno español del Atlántico comenzaba en el puerto de San Francisco"29. Pero el Rey
Prudente, que había confiado minuciosamente a Jaime Rasquin tal tarea años atrás, ya no tratará de impulsar ningún asentamiento en la costa atlántica del Brasil meridional. Tampoco parece que hayan tenido interés en hacerlo sus sucesores. $Y$ eso a pesar de que en 1609 Hernandarias de Saavedra, Gobernador del Río de la Plata y del Paraguay, denunció los frecuentes viajes realizados por los vicentinos a Santa Catarina, que proponía ocupar y fortificar, resaltando las ventajas de su puerto. Por entonces el cronista Ruy Díaz de Guzmán seguía considerando vigentes los términos que Cabeza de Vaca había señalado por el norte a su gobernación y advertía que la isla "en este tiempo está desierta porque se han ido los naturales" 30 . En 1626 el gobernador bonaerense Francisco Céspedes deseó colonizar la costa hoy uruguaya sin perder de vista Santa Catarina. Y el padre jesuita Diego de Torres propondrá crear un puerto estable en ella en 1631, cuando los paulistas ya deseaban hacer allí un núcleo de población. Ninguno de estos planes pudo verse coronado por el éxito puesto que ni siquiera fue llevado a la práctica.

Debemos tener en cuenta una serie de consideraciones a la hora de evaluar el impacto de la Unión Ibérica en las Debatable Lands, de las que Santa Catarina era una cabeza de puente insular. Se han hecho al respecto varias interpretaciones, que no tienen por qué ser mutuamente excluyentes sino complementarias. Estudios recientes sugieren que hubo escasa preocupación y relativa calma en la cuestión de las regiones fronterizas hasta que emergió con posterioridad una escalada de conflictividad más acusada entre mediados del siglo XVII y $1680^{31}$. La razón estribaría en las alianzas matrimoniales, los tratados y, por supuesto, los sesenta años de una Monarquía Dual que vino a amortiguar, si bien no a disolver, las fuentes de conflicto potencial. Esta visión es razonable siempre y cuando seamos conscientes de que las incursiones bandeirantes más allá de la línea de Tordesillas causaron episodios de violencia sobre el terreno y alarma entre muchos sectores de la administración colonial castellana, tanto en América como en Europa, y de que incluso en el siglo XVII existieron algunos proyectos para incorporar a esa administración los territorios 
en cuestión. Así como ciertos autores -vale decir clásicos- ya habían mostrado que con la unión de las dos coronas bajo un mismo cetro decreció aparentemente la importancia de conocer con exactitud cuáles eran los límites de Castilla y Portugal en América del Sur y el Tratado de Tordesillas perdió una rigidez que había sido más teórica que real -Monferini acuñó la expresión "confusión tolerada"32-, hoy se sigue reconociendo que la rivalidad luso-española en el Río de la Plata se vio condicionada por la Doble Monarquía, que tiñó de confraternización unas relaciones antes conflictivas, aunque siguiera habiendo roces ${ }^{33}$.

Posiblemente, como ha argumentado De Solano, la Guairá o "el Gran Paraguay" se convirtieran en una zona marginal en los confines de las áreas de colonización española y portuguesa debido a factores tan poderosos como la debilidad de Asunción como centro difusor de colonización, el carácter de un terreno cuya naturaleza agreste lo convertía en una barrera prácticamente infranqueable, y la renuncia de la Metrópoli a ampliar la colonización en el virreinato del Perú concentrándose en la protección de la riqueza minera ${ }^{34}$. También habría que tener en cuenta que la marginación comercial de Buenos Aires por culpa del rígido esquema de comercio colonial desincentivó la ocupación del litoral atlántico desde este nuevo centro de irradiación del poder español, cuya expansión se vio así ralentizada. Así pues, a mediados del siglo XVII, la isla de Santa Catarina, su costa adyacente y los territorios del interior no presentaban ningún poblamiento europeo de significación, ni castellano ni portugués, y sí una nebulosidad así en su geografía como en su soberanía. Fray Laureano de la Cruz -o el fraile franciscano que pudo haber escrito la obra que se le atribuyeal describir la América del Sur en torno a 1650 afirmaba que Brasil era un espacio geográfico "desde el Río de Orellana al de la Plata" que pertenecía a Portugal hasta Cananéia, y aunque consideraba español el territorio más meridional, reconocía tácitamente que más que fronterizos los auténticos "límites" eran a la sazón los del conocimiento geográfico, muy escaso:

"El distrito y jurisdicción del Río de la Plata o Paraguay, que comprende varias y dilatadas provincias, (...) al Septentrión tiene al Brasil, y por esta parte tiene inciertos sus términos respecto de haber en ellos muchas provincias que no se han reconocido. (...) La longitud y anchura de esta comarca apenas se puede reducir a cosa cierta"35.

\section{- Jesuitas Vs. Paulistas}

Una vez examinada la repercusión que la refundación de Buenos Aires pudo tener en el abandono del plan de constituir bases españolas estables en la costa meridional brasileña, veamos, en segundo lugar, otra de las dinámicas más notables desarrolladas durante la Unión Ibérica que tendrá importantes consecuencias en las Debatable Lands. Nos referimos al enfrentamiento entre bandeirantes y jesuitas que tuvo de hecho en este período su apogeo, y que ha recibido una considerable atención historiográfica ${ }^{36}$.

En la primera década del siglo XVII los jesuitas españoles comenzaron a fundar misiones en la región de Guairá al objeto de tutelar y predicar los secretos de la religión cristiana a los indios. En 1607 se creó la Provincia jesuítica del Paraguay y desde entonces se incrementará la fundación de misiones o reducciones en tres áreas: Itatim (sur de Mato Grosso), Guairá (oeste de Paraná) y, desde 1626, en el Tape (actual Rio Grande do Sul) entre las cuencas de los ríos Uruguay y Jacuí. Como los misioneros españoles consideraban el río Paranapanema como frontera septentrional, la Guairá bien pudo haber sido el límite entre los imperios español y portugués al norte del Río de la Plata. No fue así porque las reducciones no persistieron y con ello tampoco una potencial frontera nítida entre las colonias en ese lugar. Durante la época de la Unión Ibérica grupos bandeirantes surcaron el territorio entre São Paulo y Asunción en busca de indígenas que esclavizar y la Guairá empezará a desgajarse del dominio español para gravitar hacia la esfera del Brasil Colonia. Las autoridades castellanas dejaron que los jesuitas desarrollasen en la región su labor evangelizadora pero también que se defendiesen casi con sus únicas 
fuerzas. Unas fuerzas escasas ante la porfía de los bandeirantes.

Aunque se iniciaron en la segunda mitad del siglo XVI el gran siglo de las bandeiras es sin duda el XVII, y más específicamente, fue durante primera mitad de esa centuria cuando se produjo el apogeo del "bandeirismo de apresamento". La historiografía brasileña tradicional explicaba este auge como consecuencia de un déficit de mano de obra en las capitanías azucareras del Nordeste a raíz de la interrupción del tráfico atlántico de esclavos por la conquista holandesa de Angola y Recife, pero existen buenas razones para considerar, como hacía John M. Monteiro, que la clave de la expansión paulista se halla no tanto en el abastecimiento de indígenas para trabajar en los ingenios del litoral, sino en la notable carencia de mano de obra sentida a comienzos del siglo XVII en São Paulo para reproducir la fuerza de trabajo con que desarrollar una agricultura comercial $^{37}$. La pobreza de São Paulo en esa época no permitía la compra de esclavos de origen africano tal como se practicaba en las capitanías azucareras del norte; y los guaraníes adoctrinados por los jesuitas eran codiciados porque eran numerosos, hablaban la lingua geral de Brasil y había pocos españoles dispuestos a defenderlos. Por su parte, Luiz Felipe de Alencastro sigue manteniendo el núcleo de la tesis tradicional -la causa de las bandeiras reside en la ruptura del flujo de esclavos africanos y en el descenso del número de éstos-, pero al mismo tiempo se distancia de ella matizándola considerablemente. Como Monteiro, también considera que los indígenas capturados en las regiones meridionales no fueron encaminados al Nordeste, sino que fueron empleados en tareas de cultivo y transporte en São Paulo y Río de Janeiro, aunque en este caso porque el aporte de esta mano de obra venía a asegurar la provisión de las plazas costeras brasileñas, que según Alencastro se veía entonces entorpecida al estar sometida a dos tipos de presiones, concretamente la reducción de las importaciones de productos europeos desde Portugal y el incremento de la demanda alimenticia tras la llegada de guarniciones de refuerzo ${ }^{38}$.
La fase más aguda de la lucha entre bandeirantes y jesuitas se vivió entre 1628 y 1641. En poco más de diez años los bandeirantes arrasaron todas las reducciones de la Guairá y el Tape. En 1628 se ordenó a Francisco de Céspedes, gobernador de las provincias del Río de la Plata, que castigase a los habitantes de la villa de São Paulo que iban a "cautivar los indios" de las reducciones del Paraguay; y una década después, en 1639, se enviaron órdenes del mismo cariz -castigar a los paulistas que penetraban en tierras bajo su jurisdicción, disponer al instante de gente armada para perseguirles y tomar medidas tendentes a evitar futuras entradas suyas- a los gobernadores de Tucumán, Paraguay y Río de la Plata, al presidente de la Audiencia de Charcas y al virrey del Perú ${ }^{39}$. La reiteración era señal inequívoca de que durante la década de 1630 no se había podido frenar el empuje de los paulistas. En esa tesitura el virrey del Perú llegó a exponer al gobierno metropolitano de Madrid que la única forma de contener a esas "gentes que no obedecen a Dios ni al rey" era agregar al patrimonio regio el territorio perteneciente a São Paulo a cambio de una indemnización ${ }^{40}$. Los jesuitas procuraron alejarse del radio de acción de las bandeiras evacuando los pueblos de la Guairá y concentrando misiones en la región del Tape, más al sur, entre el río Uruguay y el Atlántico, y cuando los bandeirantes también llegaron ahí, pasaron a la zona entre el Paraná y el Uruguay, protegiéndose de ellos en el rincón delimitado por el curso de estos ríos. Tan sólo se salvaron las reducciones del actual territorio de Misiones (Argentina), porque Felipe IV permitió que jesuitas y misionados utilizaran armas de fuego con las que derrotaron a los bandeirantes en la batalla de Mbororé (1641).

\section{- La experiencia comercial de los portugueses en Buenos Aires}

Con la refundación de Buenos Aires se intentaba satisfacer una necesidad que no era nueva. La zona del Tucumán y el Río de la Plata había sufrido las consecuencias de la rigidez del sistema comercial monopolístico y mercantilista castellano basado en el puerto único, las rutas y calendarios fijos, y el tráfico efectuado mediante 
el sistema de flotas y galeones. El resultado de todo ello fue que los productos que llegaban a ambas zonas por la vía oficial desde Lima eran escasos y además muy caros. Las Provincias del Paraguay, Tucumán y Charcas se habían esforzado por crear un puerto atlántico que acortase las distancias de la navegación con las costas españolas y rompiese la subordinación económica con el puerto de Lima. Ya hemos visto que el proyecto de establecer ese nudo portuario permanente en la costa meridional de Brasil ni pudo llevarse a cabo antes de la Unión Ibérica ni continuó intentándose con firmeza desde que pasó a asumir esa función el de Buenos Aires.

La refundación despertó el deseo de lucro de muchos portugueses que comenzaron a comerciar con la ciudad y desató una oleada de peticiones por parte del cabildo bonaerense en demanda del derecho para comerciar con el interior -hacia las provincias de Tucumán y de Perú- y con el exterior -especialmente con Brasil-, consiguiéndolo en momentos puntuales. Portugueses y castellanos eran súbditos de un mismo monarca y a pesar de que se mantuviesen las diferencias entre ambos los intercambios se hicieron más frecuentes e intensos, especialmente en América, donde las fronteras eran más permeables. Durante la Unión Ibérica bastantes españoles se asentaron en São Paulo tomando partido por la facción de los "Camargos" enfrentada a los "Pires", y se incrementó el comercio de Brasil con el Río de la Plata, contacto favorecido lógicamente con la fundación de Buenos Aires.

Aunque los intercambios comerciales entre la América Portuguesa y la cuenca del Plata eran anteriores, desde que en 1585 el mismísimo obispo de Tucumán intentase comerciar directamente con Bahía se intensificó un tráfico tan regular con los puertos brasileños que fray Vicente do Salvador llegó a decir que "daí por diante não houve ano em que não fossem alguns navios de permissão real ou de arribada"41. En realidad, casi no podría haber sido de otra manera: la debilidad de la industria en España y el régimen de monopolio podían asfixiar el comercio de Buenos Aires tanto por desabastecimiento como por el encarecimiento de los productos. Junto a ello, había toda una serie de factores que favorecían la relación directa entre Buenos Aires y los puertos de la costa de Brasil: la costumbre de los barcos en tránsito hacia el Río de la Plata de hacer escala en Brasil, la proximidad geográfica existente entre los puertos brasileños y el estuario platino, y la enorme atracción que ejercía en Brasil el territorio del Cerro Rico del Potosí, centro extractor de una plata que Portugal necesitaba para adquirir las mercancías de Oriente y por añadidura gran mercado consumidor, con proverbial inflación y gran demanda de esclavos africanos en las minas.

Desde finales del siglo XVI aumentó el asentamiento de los colonos luso-brasileños en los núcleos urbanos coloniales españoles más importantes en el espacio que nos ocupa: Asunción, Ciudad Real, Córdoba, Buenos Aires e incluso en las localidades del Perú. A pesar de las prohibiciones vigentes muchos emigrantes portugueses en Buenos Aires se naturalizaban y adquirían cargos en la administración y la milicia. Los comerciantes de origen portugués enriquecidos en Lima, Cuzco o incluso en Buenos Aires recibían cuando regresaban a la América Portuguesa el nombre de peruleiros, signo de prestigio antes que peyorativo por el montante de plata que solían haber podido reunir ${ }^{42}$.

El comercio portugués fue especialmente floreciente en Buenos Aires, donde introducían productos a mejor precio que los de la vía monopolística oficial de El Callao. Desde la ciudad porteña salía plata, cueros y ciertos tejidos, mientras que allí se recibían procedentes de Brasil productos manufacturados europeos, herramientas agrícolas, maderas, sal, azúcar y esclavos. Según algunos informes el valor de los productos que se importaban fue veinte veces mayor que el de las exportaciones entre 1586 y $1595^{43}$, saldándose la diferencia mediante pagos con plata. Como es lógico, en calidad de puerto intermediario Buenos Aires se beneficiaba de esta pujante actividad comercial. Salvador de Bahía y en menor medida Río de Janeiro y Recife-Olinda eran centros reexportadores de manufacturas procedentes de Lisboa hacia Buenos Aires, donde los 
contrabandistas tenían agentes permanentes ${ }^{44}$. La situación era del todo intolerable para los comerciantes limeños, que presionaron ante las instituciones metropolitanas, que también deseaban evitar la riada de plata que salía de Buenos Aires rumbo a los puertos brasileños y la reducción de los ingresos fiscales derivados de la introducción de mercancías. Fue entonces cuando se expidió la Real Célula de 1594 que reforzaba el monopolio impidiendo que entrase en Buenos Aires cualquier mercancía transportada en barcos que no hubiesen salido de Sevilla. Con una excepción: para garantizar el suministro de mano de obra esclava en las minas se concedieron asientos especiales. De hecho, durante la primera mitad del siglo XVII los portugueses tuvieron la hegemonía en el tráfico legal e ilegal de esclavos que eran introducidos en la América Española.

La represión del comercio directo fue morigerada esporádicamente ante los ruegos de los bonaerenses, que en 1602 consiguieron el derecho de exportar a Brasil y Guinea y en 1618 el envío de dos navíos de permiso anuales desde Sevilla. Aunque a veces se prorrogasen a raíz de las repetidas peticiones del Cabildo de Buenos Aires, se trataba de medidas provisionales frente a la tendencia constante a favorecer los intereses de los comerciantes limeños. Para reforzarlos y evitar que mercancías de contrabando entrasen en el Alto Perú desde Buenos Aires se optó por introducir medidas más radicales, como imponer trabas a la circulación de moneda de plata en Buenos Aires y, sobre todo, el establecimiento en 1623 de una aduana en Córdoba, que estaba situada en el camino que ligaba el puerto con Tucumán y las regiones donde se extraía la plata. Con esta medida proteccionista el precio de los productos introducidos por Buenos Aires aumentaría, haciendo menos atractivo y por tanto menos cuantioso el comercio; pero a la postre la otra consecuencia será el aumento de las actividades económicas extralegales. Y así, a pesar de las restricciones con que la Corona de Castilla trataba de preservar los intereses monopolistas de los comerciantes limeños y sevillanos, el comercio de Buenos Aires siguió existiendo, menos voluminoso desde luego, a veces incluso con la connivencia de las autoridades hispanoamericanas, y con ello también permaneció la nutrida comunidad de portugueses asentados en la ciudad.

En 1643, según Lafuente Machain, un 25 $\%$ de los aproximadamente mil quinientos habitantes de Buenos Aires eran portugueses ${ }^{45}$. Esto muestra, como apuntó Alice Canabrava, que el comercio portugués halló condiciones muy favorables para la expansión durante la Monarquía Dual, aunque sea excesivo pensar que la preponderancia comercial lusa fuera tan grande en la fase central de esa etapa, entre 1585-1625, como para que el Río de la Plata se transformase "num verdadeiro rio português"46. La exageración es tan grande como cierta fue la interdependencia que llegaron a desarrollar los puertos brasileños y el de Buenos Aires.

\section{La colonia del sacramento y la conquista de Santa Catarina}

Tras la Aclamación de João IV termina de facto la Unión Ibérica. El nuevo monarca de la dinastía Bragança quiso conocer qué medidas recomendaba el gobernador de Río de Janeiro, Salvador Corréia de Sá, para restablecer las relaciones comerciales de Brasil con el Río de la Plata, donde los controles de las autoridades se habían vuelto más estrictos. Corréia de Sá no se anduvo por las ramas: propuso conquistar Buenos Aires y levantar una fortaleza cercana ${ }^{47}$. Por tres veces (1643, 1644 y 1650) se planteó en Lisboa atacar Buenos Aires desde las bases brasileñas $^{48}$. Y será precisamente Corréia de Sá quien en las décadas de 1640 y 1650 solicite centenares de leguas de tierra para poblar entre las que se contaba la isla de Santa Catarina. Estaba llegando la hora en que Portugal intentaría el poblamiento del sur de Brasil e incluso del norte del Río de la Plata. El progreso del frente de colonización meridional portugués será lento pero imparable durante la segunda mitad del siglo XVII. Paranaguá (1648) y São Francisco do Sul (1660) fueron elevadas a la condición de vilas y el bandeirante Dias Velho Jr. se instaló en Santa Catarina en 1675 después 
de haber creado allí una explotación agrícola. Cien años antes eran los castellanos quienes proyectaban crear núcleos de población en el Río de la Plata y la costa atlántica más cercana a la Guairá; desde ahora serán los portugueses quienes intenten y consigan asomarse al gran estuario, en cierta forma espoleados por la crisis en la que se sumirá la Monarquía Hispánica pero sobre todo por sus propias necesidades.

La fundación de Colonia del Sacramento en 1680 obedeció a poderosos motivos comerciales y políticos. Aunque puedan parecer destacarse las causas económicas -favorecer el comercio con las provincias hispanoamericanas- en realidad éstas van inextricablemente unidas a las territoriales -dominar esa "tierra de nadie", desde el punto de vista de la colonización iberoamericana, al norte del estuario-49. Sigue teniendo validez el diagnóstico de Mario Rodríguez: veintiocho años de guerra con España (1640-1668) habían dejado exhausto y endeudado a Portugal, que tuvo que hacer concesiones a los comerciantes extranjeros para garantizar su independencia. Don Pedro de Braganza, regente desde 1667, comprendió que los dominios portugueses más rentables ya no estaban en Oriente, donde habían interferido los holandeses, sino en Brasil, introduciendo una serie de reformas para potenciar su economía, afectada por la competencia del azúcar antillano, y de esta forma aumentar sus ingresos ${ }^{50}$. Simultáneamente, en Río de Janeiro muchos pedían reanudar el comercio con Buenos Aires creando una base en el Río de la Plata aprovechando la ausencia de colonización española en un territorio que prometía además gran riqueza agropecuaria y tal vez también valiosas minas.

El enclave fue el epicentro de un comercio extralegal tan intenso entre 1716-1757 que Capistrano de Abreu dijo que era un nido de contrabandistas ${ }^{51}$. Lógicamente la Colonia era una amenaza para los intereses de la Monarquía Hispánica en aquel lugar, por lo que las autoridades metropolitanas trataron de recuperarla o al menos impedir que fuese el primer eslabón para la total ocupación portuguesa de la Banda Oriental. Los españoles la conquistaron en 1681 y 1705 pero tuvieron que devolverla en virtud de tratados firmados en Europa. El sur y el oeste de la isla de Santa Catarina señalaban en aquel entonces de manera aproximada la frontera entre la América Portuguesa y la América Española. Para apoyar la defensa de Colonia era imprescindible desde el punto de vista portugués poblar el Rio Grande de São Pedro y consolidar una estructura de poder fuerte en la isla de Santa Catarina, que de la misma manera que había tenido importancia como base de operaciones cuando se constituyó el enclave avanzado siempre sería en adelante un punto de apoyo vital para sostener la resistencia de la Colonia del Sacramento y con ello mantener viva la idea de ocupar enteramente la Banda Oriental. Para ello también era preciso que siguiese avanzando el frente de colonización, y tal protagonismo le cupo a los habitantes de Laguna, fundada en 1684 y elevada al rango de villa en 1714, que abrieron caminos, ocuparon el suelo y contaron con el potente estímulo de la demanda en el mercado mineiro del ganado que medraba en la "campiña sulina". Sin embargo, aún hacía falta un impulso político. Éste vino, a instancias del Conselho Ultramarino, de la mano de José da Silva Paes, quien no sólo fundó un fuerte en la Laguna de los Patos (1737) sino que puso en marcha desde 1739 la capitanía de Santa Catarina -donde Nossa Senhora do Desterro ya era villa desde 1726-, diseñó un sistema de fortificaciones y solicitó el envío de emigrantes de Azores para consolidar el poblamiento.

Los españoles fundaron Montevideo y, recordando su papel como "antemural" frente a las acometidas de los paulistas en el siglo XVII, animaron a los jesuitas a restablecer misiones al este del río Uruguay. El Tratado de Madrid no podrá zanjar las luchas porque despertó tal oposición interna tanto en España como en Portugal que terminó desechándose, al menos momentáneamente, en 1761. El siguiente año, Pedro de Cevallos, gobernador de Buenos Aires, volvió a tomar Colonia pero igualmente tuvo que devolverla en virtud de los acuerdos diplomáticos. Alegando derechos del rey de España, decidió no obstante retener otros enclaves como Rio Grande de São Pedro, que durante los siguientes trece años (1763-1776) el marqués de Pombal intentará 
recuperar acumulando a tal efecto un ejército considerable. En este esquema la capitanía de Santa Catarina jugará un papel crucial: por ella pasó el material que el virrey Lavradio conducía al teatro de operaciones y de ella se sacarían víveres, materiales y todo tipo de refuerzos para el ejército de Böhm, que reconquistó Rio Grande.

En respuesta Cevallos comandó una expedición que, con 116 barcos y cerca de 10.000 militares, era la más poderosa que los españoles habían mandado hasta entonces al continente americano ${ }^{52}$. Tenía como objetivos específicos conquistar Santa Catarina y reconquistar Rio Grande de São Pedro y la Colonia del Sacramento, pero su objetivo general era solucionar el conflicto limítrofe hispano-portugués en América del Sur. A pesar de las disposiciones de Pombal y de Lavradio las defensas de la isla eran netamente inferiores para hacer frente a semejante contingente. La flota luso-brasileña abandonó las aguas de la isla, la guarnición las fortalezas, y el ejército la isla antes de que la rendición fuese firmada el 5 de marzo de 1777.

La conquista de Santa Catarina satisfizo tanto a Carlos III que aún sin conocer la conquista de la Colonia del Sacramento autorizó el cese de hostilidades y la apertura de conversaciones para restablecer la paz y solucionar la cuestión fronteriza en Suramérica. El gobierno y los diplomáticos portugueses dejaron patente su firme voluntad de recuperar la isla de Santa Catarina, tanto que el Secretario de Estado de Carlos III, el conde de Floridablanca, llegó a temer que se desbaratasen las negociaciones en curso. Para que no se torcieran decidió hacer uso como pieza de intercambio en el tablero diplomático de una isla cuya conservación Cevallos ya había advertido que resultaría onerosa a la Real Hacienda.

\section{Nuestras conclusiones}

Para finalizar señalemos algunas conclusiones que pueden derivarse de este estudio:

1. La isla de Santa Catarina siempre fue una plataforma para consolidar o bien aspirar al dominio del norte del Río de la Plata. En el siglo XVI llegarán a ella la mayoría de los barcos castellanos que iban al estuario y para consolidar el poblamiento y unir Asunción con el Atlántico la Corona de Castilla trató de fundar un asentamiento estable en la costa del actual Estado de Santa Catarina, especialmente en las cercanías del actual São Francisco do Sul. El deseo de consolidar un núcleo permanente en esta zona alcanzó su punto álgido entre 1540 y 1560 , pero las dificultades fueron insuperables. Las capitulaciones suscritas por los monarcas castellanos con Sanabria y Rasquin y el desenlace de sus expediciones así lo muestran.

2. El período de la Unión Ibérica fue determinante para que la isla pasase a la órbita portuguesa. Desde posiciones castellanas será ya escaso el interés y grande la dificultad para poblar la región de Guairá y la isla de Santa Catarina, entre otras cosas porque la incierta frontera representada por las misiones jesuitas se contrajo cuando éstos hubieron de replegarse huyendo de los bandeirantes. Las lucrativas actividades comerciales portuguesas constituirán un poderoso estímulo para la fundación de la Colonia del Sacramento, que dará impulso al avance del frente de colonización meridional luso-brasileño y hará pasar al primer plano la importancia estratégica de la isla de Santa Catarina como escala hacia el Río de la Plata, papel descuidado por la administración española.

3. Utilizando la perspectiva diacrónica y tomando como marco geográfico de análisis las Debatable Lands se entiende mejor la conquista española de la isla de Santa Catarina en 1777. Ubicada en la parte asignada a Portugal en el Tratado de 1494, pudo haber sido asimilada a la América Española en el siglo $X V I$. Aunque a inicios de su reinado Felipe II impulsó el poblamiento del litoral catarinense, 


\section{NOTAS}

dejó de hacerlo cuando se convirtió en rey de Portugal. Fue durante la Unión Ibérica cuando la Monarquía Hispánica perdió su ocasión para tomar posesión de la zona continental de la Guairá y de su fachada atlántica. En la segunda mitad del siglo XVII coincidirá el paroxismo de la decadencia española con el nuevo rumbo de la monarquía portuguesa, que pasó a considerar Brasil como la base económica de su imperio.

4. Retener la isla de Santa Catarina tras tomarla en 1777 suponía un auténtico hándicap para los españoles. En este sentido, la conquista ha de verse como una empresa tardía. Desde 1680 la isla había sido un punto de apoyo esencial en el esfuerzo portugués por sostener la Colonia del Sacramento e imponerse a los españoles en el "Continente de Rio Grande de São Pedro". Si en el siglo XVI los castellanos no habían tenido el interés ni la fuerza suficiente para lanzar las bases del poblamiento sobre la isla ni la franja continental próxima, en 1777 la vinculación de esta zona al Brasil Colonia era ya tan sólida que los españoles difícilmente podrían conservarla en su poder. Esto provocaría elevados gastos, restaría fuerzas militares en otros puntos, nunca sería bien acogida por los portugueses y añadiría una nueva pieza al ya de por sí amplio mosaico de objetivos militares que los ingleses podrían atacar en el enorme imperio español en América. La suerte de Santa Catarina se había jugado mucho tiempo atrás, concretamente doscientos años antes. Se puede afirmar que su incorporación al dominio español fue mucho más factible antes de 1580 que en 1777.

\begin{abstract}
${ }^{1}$ Este artículo recoge por extenso el contenido de la comunicación presentada en el seminario de investigación Brasil en el marco de la Monarquía Hispánica (1580-1640), celebrado el 3 de febrero de 2012 en la Facultad de Geografía e Historia de la Universidad de Salamanca y coordinado por José Manuel Santos Pérez y Ana Paula T. Megiani.

${ }^{2}$ La tesis doctoral a la que estaba orientaba la investigación, dirigida por el fundador del Centro de Estudios Brasileños, José Manuel Santos Pérez, fue defendida en el Palacio de Maldonado de Salamanca, sede de la antedicha institución, el 19 de septiembre de 2013. Ha llevado por título La ocupación española de Santa Catarina (1777-1778). Una isla brasileña para Carlos III y se encuentra disponible en formato digital: http://gredos.usal.es/jspui/handle/10366/123037.
\end{abstract}

${ }^{3}$ Dauril Alden, Royal Government in Colonial Brazil. Berkeley/Los Ángeles: University of California Press: 1968, p. 59.

${ }^{4}$ Gerald J. WHITROW, El tiempo en la historia. Barcelona: Ed. Crítica, 1990, p. 182.

${ }^{5}$ Max Justo GUEDES, "O Descobrimento do Brasil e o Tratado de Tordesilhas", en VV.AA., El Tratado de Tordesillas y su época, vol. 3. Valladolid: Sociedad V Centenario del Tratado de Tordesillas/Junta de Castilla y León, 1995, pp. 1401-1415, p. 1402.

${ }^{6}$ Júlio R. QUEVEDO DOS SANTOS, "A ocupação européia do Rio Grande do Sul: séculos XVII e XVIII", en Ana Beatriz B. GONÇALVES y Claudete BOFF, Turismo e Cultura. História Regional. Santo Ângelo: Gráfica Venâncio Ayres, 2001, pp. 71-87, p. 73.

${ }^{7}$ Leyla PERRONE-MOISÉS, "Essomericq, o venturoso carijó", en Adauto NOVAES (Org.), A outra margem do Ocidente. São Paulo: Companhia das Letras, 1999, pp. 335-350, pp. 335-337.

${ }^{8}$ Rodrigo L. SIMAS DE AGUIAR, "Cronistas europeus e a etno-história carijó na llha de Santa Catarina", en Ángel B. ESPINA BARRIO (ed.), Antropología en Castilla y León e Iberoamérica, IV. Cronistas de Indias. Salamanca: Ed. Universidad de Salamanca, 2002, pp. 329-336, pp. 329-331.

${ }^{9}$ Enrique de GANDÍA, "Descubrimiento del Río de la Plata, del Paraguay y del estrecho de Magallanes", en R. LEVENE, Historia de la nación argentina, vol. II. Buenos Aires: El Ateneo, 1940, pp. 397-435, pp. 404410.

${ }^{10}$ Vid. Ángel SANZ TAPIA, "La aculturación indígena: Los primeros españoles indianizados", en Actas del Congreso de Historia del Descubrimiento (1492-1556), tomo II. Madrid: Real Academia de la Historia, 1992, pp. 303-368, pp. 348-351.

${ }^{11}$ Cesáreo FERNÁNDEZ DURO, "Los Cabotos". Boletín de la Real Academia de la Historia, vol. 22 (1893), pp. 257-282, pp. 268 
${ }^{12}$ La Relación y Comentarios del Governador Alvar Núñez Cabeza de Vaca de lo acaescido en las dos jornadas que hizo a las Indias. Valladolid: Francisco Fernández de Córdova, 1555, Folio LIX.

${ }^{13}$ Ibidem, f. LXI.

${ }^{14}$ Ibidem, f. LXIII.

${ }^{15}$ Capitulación con Juan de Sanabria. Monzón, 22/07/1547. Archivo General de Indias [AGI], Sección Indiferente General, Legajo 415, ff. 167V-172V.

${ }^{16}$ Real Cédula a Juan López. Valladolid, 4/8/1550. AGI, Indiferente General, 424, Libro 22, f.. 183.

17 Tomé de Souza a João III. Salvador, 1/06/1553. Apud Arquivo Nacional da Torre do Tombo, As gavetas da Torre do Tombo, vol. 9. Lisboa: Centro de Estudos Históricos Ultramarinos, 1971, pp. 203-208, p. 207.

${ }^{18}$ Robert SOUTHEY, History of Brazil, vol. 3. Londres: Longman, 1819, p. 646.

${ }^{19}$ Capitulación con Jaime Rasquin, 30/12/1557. AGI, Indiferente General, 415, 1, ff. 162R-167V, f. 162.

${ }^{20}$ Representación de Jaime Rasquin. S. d. AGI, Patronato Real, 29, Ramo 10, Documento 3.

${ }^{21}$ Parecer de Jaime Rasquin. S. d. AGI, Patronato Real, 29, Ramo 10, Documento 2.

22 Ibidem.

${ }^{23}$ Para los pormenores de esta expedición véase Enrique de GANDÍA, Aventuras de Jaime Rasquin. Buenos Aires: Emecé Editores, 1943.

${ }^{24}$ Primera capitulación con Juan Ortiz de Zárate. Madrid 10/7/1569. AGI, Patronato Real, 29, Ramo 22.

${ }^{25}$ Relación del viaje de Juan Pinto al Río de la Plata. S.d. AGI, Patronato Real, 29, Ramo 36.

${ }^{26}$ Para una aproximación a la Unión Ibérica son de especial interés -entre otros- los siguientes trabajos: Ricardo E. DOS SANTOS, El Brasil filipino: 60 años de presencia española en Brasil (1580-1640). Madrid: Mapfre, 1993; Rafael VALLADARES, Portugal y la Monarquía Hispánica, 1580-1688. Madrid: Arco Libros, 2000; Roseli S. STELLA, O domínio espanhol do Brasil durante a monarquía dos Felipes (1580-1640). São Paulo: Unibero, 2000; Fernando BOUZA ÁLVAREZ, Portugal en la Monarquía hispánica (1580-1640). Madrid: Universidad Complutense, 1987; Joaquín Veríssimo SERRÃO, Do Brasil Filipino ao Brasil de 1640. São Paulo: Companhia Editora Nacional, 1968; Stuart B. SCHWARTZ, «LusoSpanish relations in Habsburg Brazil, 1580-1640». The Americas, XX (1968), pp. 33-48; Antônia F. de ALMEIDA WRIGHT y Astrogildo de MELLO, "O Brasil no período dos Filipes (1580-1640)", en Sérgio BUARQUE DE HOLANDA, História Geral da Civilização Brasileira, tomo I, vol. 1. São Paulo: Difusão Européia do Livro, 1960, pp. 176-189.
27 Joaquín Veríssimo SERRÃO, "Do Brasil filipino ao Brasil de 1640", en Ana M. CARABIAS (Ed.), Las relaciones entre Portugal y Castilla en la época de los descubrimientos y la expansión colonial. Salamanca: Ed. Universidad de Salamanca/Sociedad V Centenario del Tratado de Tordesillas, 1994, pp. 319-325, p. 321.

${ }^{28}$ Rafael VALLADARES, "Brasil: de la Unión de Coronas a la crisis de Sacramento (1580-1680)", en José Manuel SANTOS PÉREZ (Ed.), Acuarela de Brasil, 500 años después. Seis ensayos sobre la realidad histórica y económica brasileña. Salamanca: Ed. Universidad de Salamanca, 2000, pp. 23-36, p. 27.

${ }^{29}$ Apud Affonso de E. TAUNAY, Em Santa Catharina Colonial. Capítulo da história do povoamento. São Paulo: Imprensa Official do Estado, 1936, p. 16.

${ }^{30}$ Ruy DÍAZ DE GUZMÁN, Historia Argentina. El descubrimiento, población y conquista del Río de la Plata escrita por Rui Díaz de Guzmán en el año de 1612. Buenos Aires: Imprenta del Estado, 1835, p. 5.

${ }^{31}$ María Eugenia PETIT-BREUILH, "Comportamientos hispanoportugueses en los territorios limítrofes de América durante los conflictos bélicos", en David GONZÁLEZ CRUZ (Coord.), Propaganda y mentalidad bélica en España y América durante el siglo XVIII. Madrid: Ministerio de Defensa, 2007, pp. 165-196, p. 174.

32 João CAPISTRANO DE ABREU, Capítulos de História Colonial (1500-1800). Río de Janeiro: Livraria Briguiet, 1954, pp. 283-304, p. 285; Juan MONFERINI, "La historia militar durante los siglos XVII y XVIII", en R. LEVENE, Historia de la nación argentina, vol. IV. Buenos Aires: El Ateneo, 1940, pp. 221-311, p. 242.

${ }^{33}$ Diego TÉLLEZ ALARCIA, La manzana de la discordia. Historia de la Colonia del Sacramento desde la fundación portuguesa hasta la conquista por los españoles (1677-1777). Barcelona: Ed. Rubeo, 2008, pp. 20-23.

${ }^{34}$ Francisco DE SOLANO, "Contactos

hispanoportugueses en América a lo largo de la frontera brasileña, (1500-1800)", en Francisco DE SOLANO y Salvador BERNABEU (Coords.), Estudios (Nuevos y Viejos sobre la frontera), Anexo de Revista de Indias. Madrid: CSIC, 1991, pp. 187-215.

${ }^{35}$ Laureano DE LA CRUZ, Descripción de la América austral, s.d., Biblioteca Nacional de España, Mss. 2950, f. 21r. El manuscrito ha sido editado: Julián Heras y Laura Gutiérrez (Eds.), Fray Laureano de la Cruz, ofm. Descripción de los reinos del Perú con particular noticia de lo hecho por los franciscanos. Lima: Pontificia Universidad Católica del Perú-Banco Central de Reserva del Perú, 1999.

${ }^{36}$ John HEMMING, Red gold: the conquest of the Brazilian Indians. Londres: Papermac, 1995, pp. 241-287; John Manuel MONTEIRO, Negros da terra. Índios e bandeirantes nas origens de São Paulo. São 
Paulo: Companhia das Letras, 1994; Arno ALVAREZ KERN, "Nas Fronteiras do Brasil Meridional: Jesuítas, Bandeirantes e Guaranis". Océanos, no 40 (1999), pp. 112-126; Myriam ELLIS, "As bandeiras na expansão territorial de Brasil", en Sérgio BUARQUE DE HOLANDA, História geral da civilização brasileira, tomo I, vol. 1. São Paulo: Difel, 1960, pp. 273-296; Basílio de MAGALHÃES, Expansão Geográfica do Brasil Colonial. São Paulo: Companhia Editora Nacional, 1978 [1944], pp. 88-129.

${ }^{37}$ John Manuel MONTEIRO, Op. cit., pp. 77 y 98.

${ }^{38}$ Luiz Felipe de ALENCASTRO, O trato dos viventes. Formação do Brasil no Atlântico Sul. São Paulo: Companhia das Letras, 2000, pp. 194-199.

${ }^{39}$ Real Cédula a Francisco de Céspedes. Madrid, 12/9/1628. AGI, Buenos Aires, 2, Libro 5, ff. 201-202; Reales Cédulas a Francisco de Avendaño, Pedro Lugo, Mendo de la Cueva, Juan de Lizarazu, y al marqués de Mancera, Pedro Álvarez de Toledo. Madrid, 16/9/1639. Ibidem, ff. 279-280.

40 José L. MÚZQUIZ DE MIGUEL, El Conde de Chinchón. Virrey del Perú. Madrid: CSIC, 1945, p. 146.

${ }^{41}$ Fr. Vicente DO SALVADOR, História do Brasil (15001627). Belo Horizonte/São Paulo: Itatiaia/ Edusp, 1982, p. 251.

42 Pedro CALMON, "Buenos Aires e o Brasil". Revista do Instituto Histórico e Geográfico Brasileiro, n 334 (1982), pp. 139-143, pp. 139-140.

${ }^{43}$ Emanuel SOARES DA VEIGA GARCIA, O Comércio Ultramarino Espanhol no Prata. São Paulo: Ed. Perspectiva, 1982, p. 23.

${ }^{44}$ Alice P. CANABRAVA, O comércio português no Rio da Prata (1580-1640). Belo Horizonte/São Paulo: Ed. Itatiaia/Ed. da USP, 1984, passim.

${ }^{45}$ Ricardo LAFUENTE MACHAIN, Los portugueses en Buenos Aires (siglo XVII). Buenos Aires: Librería Cervantes, 1931, pp. 86-87.

${ }^{46}$ Alice P. CANABRAVA, Op. cit., p. 148.

${ }^{47}$ Luís NORTON, "Os planos que Salvador Correia de Sá e Benevides apresentou em 1643 para se abrir o comercio con Buenos Aires e reconquistar o Brasil e Angola". Separata de la revista Brasília, vol. 2, 1943 , pp. 594-613; Maria Cristina LANÇA DE MORAIS, "Os portugueses na região platina, depois da restauração: dos planos de Salvador Correia de Sá à reabertura do comércio intercolonial (1640-1670)", en A. MAILHE y E. REITANO (Comps.), Pensar Portugal: Reflexiones sobre el legado histórico y cultural del mundo luso en Sudamérica. La Plata: Facultad de Humanidades y Ciencias de la Educación, UNLP, 2008, pp. 79-94, pp. 85-88; Marcello José GOMES LOUREIRO, "'Se pode intentar a conquista do Rio da Prata': O Conselho de Guerra, o Conselho Ultramarino e os alvitres para a invasão de Buenos Aires (1640-1648)". Revista Brasileira de História Militar, $\mathrm{n}^{\circ} 6$ (Diciembre 2011), pp. 1-24, p. 18.

${ }^{48}$ Rafael VALLADARES, "El Brasil y las Indias Españolas durante la sublevación de Portugal (1640-1668)". Cuadernos de Historia Moderna, vol. 14 (1993), pp. 151-172, pp. 161-162.

${ }^{49}$ Fabrício PEREIRA PRADO, A Colônia do Sacramento. $O$ extremo sul da América portuguesa. Porto Alegre: Pallotti, 2002, passim; Paulo César POSSAMAI, "A fundação da Colônia do Sacramento". Mneme, vol. 5, no 12 (2004), pp. 1-27, p. 22; Corcino MEDEIROS DOS SANTOS, Economía e Sociedade do Rio Grande do Sul. Século XVIII. São Paulo: Ed. Nacional, 1984, p. 148; Sérgio BUARQUE DE HOLANDA, "A Colônia do Sacramento e a expansão no extremo sul", en História Geral da civilização brasileira, tomo I, vol. 1. São Paulo: Difel, 1960, pp. 322-363, pp. 322 y 341; Diego TÉLLEZ ALARCIA, Op. cit., pp. 27-28.

${ }^{50}$ Mario RODRIGUEZ, "Dom Pedro of Braganza and Colônia do Sacramento, 1680-1705". HispanicAmerican Historical Review, vol. 38, $\mathrm{n}^{\circ} 2$ (mayo 1958), pp. 179-208, pp. 180-183.

${ }^{51}$ João CAPISTRANO DE ABREU, Op. cit., p. 287.

${ }^{52}$ Ángel SANZ TAPIA, El final del Tratado de Tordesillas: La expedición del virrey Cevallos al Río de la Plata. Valladolid: Junta de Castilla y León/Sociedad V Centenario del Tratado de Tordesillas, 1994, p. 90. 


\section{BIBLIOGRAFÍA}

ALDEN, Dauril. Royal Government in Colonial Brazil. Berkeley/Los Ángeles: University of California Press: 1968.

ALENCASTRO, Luiz Felipe de. O trato dos viventes. Formação do Brasil no Atlântico Sul. São Paulo: Companhia das Letras, 2000.

ALVAREZ KERN, Arno. Nas Fronteiras do Brasil Meridional: Jesuítas, Bandeirantes e Guaranis. Océanos, n 40, 1999.

Arquivo Nacional da Torre do Tombo. As gavetas da Torre do Tombo, vol. 9. Lisboa: Centro de Estudos Históricos Ultramarinos, 1971.

CALMON, Pedro. Buenos Aires e o Brasil. Revista do Instituto Histórico e Geográfico Brasileiro, nº 334, 1982.

CANABRAVA, Alice P. O comércio português no Rio da Prata (1580-1640). Belo Horizonte/São Paulo: Ed. Itatiaia/Ed. da USP, 1984.

CAPISTRANO DE ABREU, João. Capítulos de História Colonial (1500-1800). Río de Janeiro: Livraria Briguiet, 1954.

DE SOLANO, Francisco. Contactos hispanoportugueses en América a lo largo de la frontera brasileña, (1500-1800), en Francisco DE SOLANO y Salvador BERNABEU (Coords.). Estudios (Nuevos y Viejos sobre la frontera), Anexo de Revista de Indias. Madrid: CSIC, 1991.

DE LA CRUZ, Laureano. Descripción de la América austral, s.d., Biblioteca Nacional de España, Mss. 2950, f. 21r, en Julián Heras y Laura Gutiérrez (Eds.). Fray Laureano de la Cruz, ofm. Descripción de los reinos del Perú con particular noticia de lo hecho por los franciscanos. Lima: Pontificia Universidad Católica del Perú-Banco Central de Reserva del Perú, 1999.

DÍAZ DE GUZMÁN, Ruy. Historia Argentina. El descubrimiento, población y conquista del Río de la Plata escrita por Rui Díaz de Guzmán en el año de 1612. Buenos Aires: Imprenta del Estado, 1835.

DO SALVADOR, Fr. Vicente. História do Brasil (15001627). Belo Horizonte/São Paulo: Itatiaia/ Edusp, 1982.

ELLIS, Myriam. As bandeiras na expansão territorial de Brasil, en Sérgio Buarque de HOLANDA. História geral da civilização brasileira, tomo I, vol. 1. São Paulo: Difel, 1960.

FERNÁNDEZ DURO, Cesáreo. Los Cabotos. Boletín de la Real Academia de la Historia, vol. 22, 1893.

GANDÍA, Enrique de. Aventuras de Jaime Rasquin. Buenos Aires: Emecé Editores, 1943.

Descubrimiento del Río de la Plata, del Paraguay y del estrecho de Magallanes, en R. GOMES LOUREIRO, Marcello José. Se pode intentar a conquista do Rio da Prata. O Conselho de Guerra, o Conselho Ultramarino e os alvitres para a invasão de Buenos Aires (1640-1648). Revista Brasileira de História Militar, $n^{\circ} 6$, Diciembre 2011.

GUEDES, Max Justo. O Descobrimento do Brasil e o Tratado de Tordesilhas, en VV.AA. El Tratado de Tordesillas y su época, vol. 3. Valladolid: Sociedad V Centenario del Tratado de Tordesillas/Junta de Castilla y León, 1995.

HEMMING, John. Red gold: the conquest of the Brazilian Indians. Londres: Papermac, 1995.

MONTEIRO, John Manuel. Negros da terra. Índios e bandeirantes nas origens de São Paulo. São Paulo: Companhia das Letras, 1994

HOLANDA, Sérgio Buarque de. A Colônia do Sacramento e a expansão no extremo sul, en História Geral da civilização brasileira, tomo I, vol. 1. São Paulo: Difel, 1960

LAFUENTE MACHAIN, Ricardo. Los portugueses en Buenos Aires (siglo XVII). Buenos Aires: Librería Cervantes, 1931.

LANÇA DE MORAIS, Maria Cristina. Os portugueses na região platina, depois da restauração: dos planos de Salvador Correia de Sá à reabertura do comércio intercolonial (1640-1670), en A. LEVENE. Historia de la nación argentina, Vol. II. Buenos Aires: El Ateneo, 1940.

MAILHE y E. REITANO (Comps.). Pensar Portugal: Reflexiones sobre el legado histórico y cultural del mundo luso en Sudamérica. La Plata: Facultad de Humanidades y Ciencias de la Educación, UNLP, 2008.

MAGALHÃES, Basílio de. Expansão Geográfica do Brasil Colonial. São Paulo: Companhia Editora Nacional, 1978 [1944]

MEDEIROS DOS SANTOS, Corcino. Economía e Sociedade do Rio Grande do Sul. Século XVIII. São Paulo: Ed. Nacional, 1984.

MONFERINI, Juan. La historia militar durante los siglos XVII y XVIII, en R. LEVENE. Historia de la nación argentina, vol. IV. Buenos Aires: El Ateneo, 1940.

MÚZQUIZ DE MIGUEL, José L. El Conde de Chinchón. Virrey del Perú. Madrid: CSIC, 1945.

NORTON, Luís. Os planos que Salvador Correia de Sá e Benevides apresentou em 1643 para se abrir o comercio con Buenos Aires e reconquistar o Brasil e Angola. Separata de la revista Brasília, vol. 2, 1943.

PEREIRA PRADO, Fabrício. A Colônia do Sacramento. $O$ extremo sul da América portuguesa. Porto Alegre: Pallotti, 2002.

PETIT-BREUILH, María Eugenia. Comportamientos hispanoportugueses en los territorios limítrofes de 
América durante los conflictos bélicos, en David GONZÁLEZ CRUZ (Coord.). Propaganda y mentalidad bélica en España y América durante el siglo XVIII. Madrid: Ministerio de Defensa, 2007.

POSSAMAI, Paulo César. A fundação da Colônia do Sacramento. Mneme, vol. 5, no 12, 2004.

QUEVEDO DOS SANTOS, Júlio R. A ocupação européia do Rio Grande do Sul: séculos XVII e XVIII, en Ana Beatriz B. GONÇALVES y Claudete BOFF. Turismo e Cultura. História Regional. Santo Ângelo: Gráfica Venâncio Ayres, 2001.

PERRONE-MOISÉS, Leyla. Essomericq, o venturoso carijó, en Adauto NOVAES (Org.). A outra margem do Ocidente. São Paulo: Companhia das Letras, 1999.

RODRIGUEZ, Mario. Dom Pedro of Braganza and Colônia do Sacramento, 1680-1705. Hispanic-American Historical Review, vol. 38, n² 2, mayo 1958.

SANZ TAPIA, Angel. El final del Tratado de Tordesillas: La expedición del virrey Cevallos al Río de la Plata. Valladolid: Junta de Castilla y León/Sociedad V Centenario del Tratado de Tordesillas, 1994.

SANZ TAPIA, Ángel. La aculturación indígena: Los primeros españoles indianizados, en Actas del Congreso de Historia del Descubrimiento (1492-1556). Tomo II. Madrid: Real Academia de la Historia, 1992.

SERRÃO, Joaquín Veríssimo. Do Brasil filipino ao Brasil de 1640, en Ana M. CARABIAS (Ed.). Las relaciones entre Portugal y Castilla en la época de los descubrimientos y la expansión colonial. Salamanca: Ed. Universidad de Salamanca/Sociedad V Centenario del Tratado de Tordesillas, 1994.

SIMAS DE AGUIAR, Rodrigo L. Cronistas europeus e a etno-história carijó na llha de Santa Catarina, en Ángel B. ESPINA BARRIO (ed.). Antropología en Castilla y León e Iberoamérica, IV. Cronistas de Indias. Salamanca: Ed. Universidad de Salamanca, 2002.

SOARES DA VEIGA GARCIA, Emanuel. O Comércio Ultramarino Espanhol no Prata. São Paulo: Ed. Perspectiva, 1982.

SOUTHEY, Robert. History of Brazil, vol. 3. Londres: Longman, 1819.

TÉLLEZ ALARCIA. Diego, La manzana de la discordia. Historia de la Colonia del Sacramento desde la fundación portuguesa hasta la conquista por los españoles (1677-1777). Barcelona: Ed. Rubeo, 2008.

VALLADARES, Rafael. Brasil: de la Unión de Coronas a la crisis de Sacramento (1580-1680), en José Manuel SANTOS PÉREZ (Ed.), Acuarela de Brasil, 500 años después. Seis ensayos sobre la realidad histórica y económica brasileña. Salamanca: Ed. Universidad de Salamanca, 2000.
VALLADARES, Rafael. El Brasil y las Indias Españolas durante la sublevación de Portugal (1640-1668). Cuadernos de Historia Moderna, vol. 14, 1993.

WHITROW, Gerald J. El tiempo en la historia. Barcelona: Ed. Crítica, 1990. 